\title{
Annual Report on the Journal Munibe Antropologia-Arkeologia 2018
}

In 2018, we systematically included the new features introduced the previous year, particularly the new referencing system (HARVARD system, adapted to the requirements of the ELSEVIER network of journals), which is comparable with the systems used by other journals in our field of knowledge and which allows the use of the most common referencing applications almost automatically. This new system also reduces the number of pages devoted to references significantly and therefore more papers can be included in each issue of the journal.

Thirty-three original manuscripts were submitted to the journal in the course of 2018, which were added to two that finally remained unpublished in the 2017 paper edition. Due to similar circumstances, nine manuscripts could not be reviewed in time, and will be assessed in 2019. Therefore, a total of 26 manuscripts were considered for this paper edition. Each manuscript was assessed by at least two external reviewers, with a third opinion added in some cases. Six manuscripts were rejected for diverse reasons and another two papers were published directly. The other eighteen published in this issue can be divided into those that needed a profound revision (8) and the ones for which minor changes sufficed (10). The average time between receiving the acknowledgement of receipt signed by the corresponding author and the final decision whether to publish the paper or not was 29 weeks, although this varied greatly depending on several factors, such as the length and topic of the paper. Except in cases where the manuscript dealt with a topic that was not aligned with the areas of the journal, the rejections were accompanied by the negative reports of the reviewers and the opinion of the guest editor. The authors tended to take issue with those reports.

The reviewing system was again the double blind method, in which neither the authors know the identity of the reviewers nor these know who wrote the manuscripts they are assessing. This meant that each manus- cript had to be edited to remove any indication of the author(s) to the reviewers: references to the authors, citations in the text (replaced by the text "self-citation", to avoid breaking the thread of the argument), acknowledgements and bibliography cited. All the agents (guest editors, external reviewers and authors) were fully informed in writing about the reviewing mechanisms that would be applied and were given precise instructions for each step in the process, including a template to guide the reviewers' reports. As far as possible, communications between all the agents has been carried out electronically, and each author signed an acknowledgement of receipt for their manuscript, with the date given at the head of each paper, accepting the protocol described above.

The addition of DOI codes to the papers is improving their visibility in Internet substantially, as can be seen in the records monitoring them in Google Scholar. Since 1990 until the time this report was written (29 December 2018), the papers published in Munibe Antropologia-Arkeologia since 1983 have been cited 4,645 times (compared with 4,018 times, up to last year). 2,323 of these citations have been made in the last five years (contrasting with 1,840 in the five years 21022016). The papers published in the period 2013-2017 (86 papers) have already been cited 154 times, which provides an impact factor for the journal in the last five years of 1.79 citations per published paper. Any author can verify in this application the number of times that their paper has been referenced and the context of the citation. In this same period, the most often cited paper (12 times) was published in 2013 by Andrés Menéndez Blanco, David González Álvarez, Valentín Álvarez Martínez and Jesús Ignacio Jiménez Chaparro: A low-cost archaeological survey method for the detection of Roman army marching camps: the case of Western Cantabrian Mountains".

Alvaro Arrizabalaga. Chief Editor

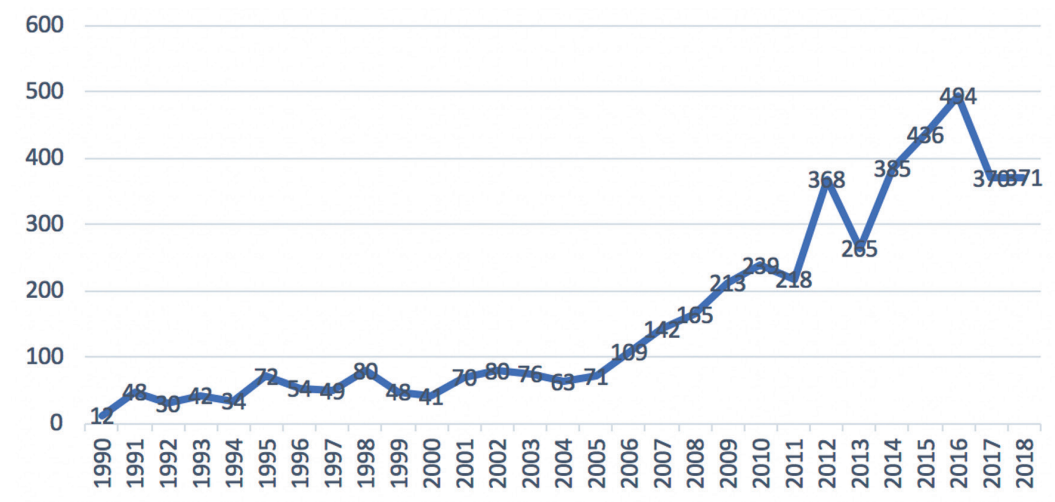

Citations to the Munibe AA journal in different academic media per year. 


\section{Munibe Antropologia-Arkeologia 2018 aldizkariaren kronika}

2018an, sistematikoki txertatu ditugu aurreko urtean etorritako berrikuntzak, bereziki, bibliografiaren idazkera berria (HARVARD sistema, ELSEVIER aldizkari-sarearen eskakizunei egokitua), gure ezagutza-eremuko aldizkariek erabiltzen dutenarekin homologagarriagoa baita, eta aukera ematen baitu aipuetarako ohiko aplikazioak ia modu automatizatuan erabiltzeko. Idazkera berriak, gainera, bibliografiari eskainitako orri kopurua asko murrizteko aukera ematen du eta hala, argitaratutako ale bakoitzeko, artikulu gehiago izan ditzake aldizkariak.

2018an, hogeita hamahirua jatorrizko artikulu jaso ditugu aldizkariaren erredakzioan balorazioa jasotzeko, eta horiez gain, 2017an, paperezko edizioan argitaratu ezin izan ziren bi ere bagenituen. Orduko gorabeheren antzekoak medio, ezin izan ditugu jatorrizko bederatzi lan garaiz ebaluatu eta 2019an ebaluatzeko zain gelditu dira. Hala, ale honetarako, hogeita sei idatzi baloratu ditugu guztira. Jatorrizko artikuluetako bakoitzak, gutxienez, kanpoko bi berrikusketa jaso ditu. Gainera, kasu batzuetan, hirugarren iritzi bat ere izan da. Horietako sei baztertuta gelditu dira, zenbait arrazoi direla-eta. Bi artikulu zuzenean argitaratu ahal izan dira. Ale honetan argitaratutako gainerako hemezortzietatik zortzik aldaketa handiak behar izan dituzte, eta hamarrek, berriz, nahikoa izan dute aldaketa txikiekin. Korrespondentziaren egileak sinatutako hartu-agiria jasotzearen eta artikulua argitaratzeko edo ez argitaratzeko erabakiaren arteko batez besteko epea hogeita bederatzi astekoa da. Dena den, epe hori oso aldakorra izaten da artikuluaren luzeraren edo gaiaren moduko faktore ugarien arabera. Testua aldizkariari dagozkion arloetatik kanpokoa ez bada behintzat, idatziak baztertu egin direla adierazteko jakinarazpenarekin batera, berrikusleen txosten negatiboak eta editore gonbidatuaren iritzia ere igortzen dizkiegu egileei eta haiek, askotan, ez dira agiri horietan adierazitakoarekin ados agoten.

Erabilitako berrikusketa-sistema, beste behin, itsu bikoitzekoa izan da. Horren bidez, egileek ezin dute jakin zein den berrikusleen nortasuna eta berrikusleek ere ezin dute jakin zein den ebaluatutako idatzien egi- leen nortasuna. Hala, testuak, banan-banan, editatu egin behar izan dira ebaluatzaile izango zirenek egileen arrastorik ikus ez zezaten: egileen erreferentziak, bidaltze-markak testuan ("Autoaipua" hitza jarri dugu horrelakoen ordez), esker onak eta aipu bibliografikoak. Eragile guztiei (gonbidatutako editoreak, kanpoko berrikusleak eta egileak) eman zaie idatzizko informazioa garatu beharreko ebaluazio-mekanismoen inguruan. Gainera, prozesuaren fase bakoitzerako jarraibide zehatzak jaso dituzte, ebaluatzaileen argibideen inguruko gutxi gorabeherako txantiloia barne. Ahal izan den neurrian, eragile guztien arteko harremanak bide elektronikoaren bidez bizkortu dira, nahiz eta egile bakoitzak bere jatorrizko dokumentuaren hartu-agiria sinatu duen artikulu bakoitzaren goiburuan data kontsignatuta eta hemen zehaztutako protokoloa onartuta.

Artikuluei DOI kodeak jarrita hobetu egiten zaie sareko ikusgarritasuna. Asko ari da hobetzen; hala erakutsi digute Google Akademikoa (Google Scholars) delakoaren kontrol-erregistroek. 1990. urtetik testu hau idatzi dugun unera arte (2018ko abenduak 29), Munibe Antropologia-Arkeologia aldizkariko artikuluak (1983. urtetik) 4.645 aldiz aipatu dira (iaz 4.018 aldiz) eta horietatik 2.323 azken bost urteetan (1.840 duela urtebete). 2013-2017 aldian argitaratutako artikuluak (86 artikulu) dagoeneko 154 aldiz aipatu izan dituzte; horrek guztiak aldizkariaren inpaktu-faktorea eskaintzen digu eta hauxe da: azken bost urteotan, argitaratutako artikulu bakoitzeko 1,79 aipu. Edozein egilek kontsulta dezake aplikazio horretan bere artikulua zenbat aldiz eta zer testuingurutan aipatu izan duten. Aipatu dugun aldian, aipu gehien jaso dituen artikulua (hamabi aipu) Andrés Menéndez Blancok, David González Álvarezek, Valentín Álvarez Martínezek eta Jesús Ignacio Jiménez Chaparrok 2013an argitaratutako hau izan da: "Propuestas de prospección de bajo coste para la detección de campamentos romanos de campaña. El área occidental de la Cordillera Cantábrica como caso de estudio".

\section{Alvaro Arrizabalaga. Editore nagusia}

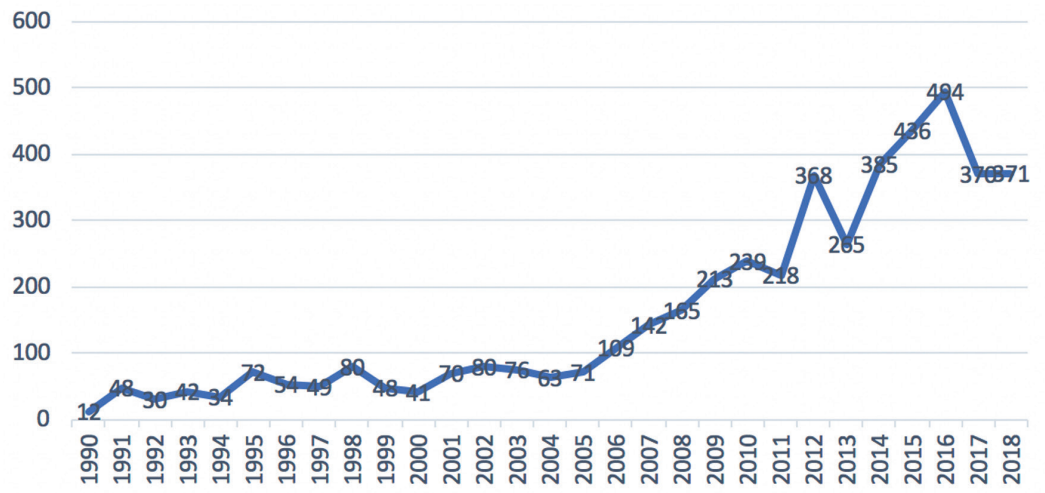

Munibe AA aldizkariaren inguruko aipuak baliabide akademiko ugaritan urte bakoitzean. 


\section{Crónica de la revista Munibe Antropologia-Arkeologia 2018}

A lo largo de 2018 hemos incorporado de modo sistemático las novedades introducidas el pasado año, en particular, la nueva notación bibliográfica (sistema HARVARD, adaptado a los requisitos de la red de revistas ELSEVIER), más homologable con la empleada por diferentes revistas de nuestro campo del conocimiento y que permite recurrir a las aplicaciones habituales de citación, de un modo casi automatizado. La nueva notación permite además un ahorro importante en el número de páginas dedicadas a la bibliografía, dando cabida en la revista a más artículos por número editado.

A lo largo de 2018 se han depositado en la redacción de la revista treinta y tres originales para su consideración, que se unen a los dos que no pudieron editarse finalmente en la edición en papel de 2017. Debido a circunstancias similares, no hemos podido evaluar a tiempo nueve originales, quedando para su consideración en 2019. Así pues, el total de manuscritos valorados para este número en papel es de veintiseis. Cada uno de los originales ha recibido un mínimo de dos revisiones externas, incorporándose en algunos casos una tercera opinión. Seis de ellos han sido rechazados por diferentes motivos. Dos artículos se han podido publicar directamente. Los dieciocho restantes editados en este número se dividen entre los que han requerido cambios mayores (ocho) y en los que ha bastado con cambios menores (diez). El periodo medio entre la recepción del acuso de recibo firmado por el autor de correspondencia y la decisión final acerca de la publicación o no del artículo se sitúa en veintinueve semanas, aunque resulta muy variable en función a distintos factores como la longitud o temática del artículo. Salvo alineamiento del manuscrito fuera de las áreas de la revista, los rechazos van acompañados de los informes negativos de los revisores y la opinión del propio editor invitado del mismo, documentos con los que los autores van a discrepar de modo habitual.

El sistema de revisión empleado ha sido nuevamente el de doble ciego, lo que impide, tanto a los autores conocer la identidad de los revisores, como a estos, conocer la de los autores de los manuscritos evaluados.
Esto ha obligado a editar cada manuscrito para eliminar cualquier rastro del / de los autores a los eventuales evaluadores: referencias de los autores, llamadas en el texto (sustituidas por la expresión "Autocita", para no romper el discurso), agradecimientos y citas bibliográficas. Todos los agentes (editores invitados, revisores externos y autores) han sido puntualmente informados por escrito de los mecanismos de evaluación que se iban a desarrollar y han dispuesto de instrucciones precisas para cada fase del proceso, incluyendo una plantilla orientativa de indicaciones de los evaluadores. En la medida de lo posible, las relaciones entre todos los agentes se han agilizado por la vía electrónica, aunque cada autor ha firmado un acuse de recibo de su original, con la fecha consignada en la cabecera de cada artículo, aceptando el protocolo aquí detallado.

La dotación de códigos DOI a los artículos viene incrementando su visibilidad en la red, que va mejorando sustancialmente tal y como observamos en los registros de control de Google Académico. Desde el año 1990, hasta la redacción de este texto (29 de diciembre de 2018), los diferentes artículos de Munibe Antropologia-Arkeologia (desde 1983) han sido citados 4645 veces (frente a 4018 veces, el año pasado), 2323 de las cuales durante los últimos cinco años (por 1840 hace un año). Los artículos publicados durante el periodo 20132017 (86 artículos) han sido citados ya 154 veces, lo que nos proporciona el factor de impacto de la revista, para los últimos cinco años, de 1,79 citas por artículo editado. Cualquier autor puede consultar en esta aplicación el número de veces que su artículo ha sido citado y en qué contexto lo ha sido. Para el periodo reciente citado, el artículo más citado (en doce ocasiones) ha sido el publicado en 2013 por Andrés Menéndez Blanco, David González Álvarez, Valentín Álvarez Martínez y Jesús Ignacio Jiménez Chaparro, "Propuestas de prospección de bajo coste para la detección de campamentos romanos de campaña. El área occidental de la Cordillera Cantábrica como caso de estudio".

\section{Alvaro Arrizabalaga. Editor Principal}

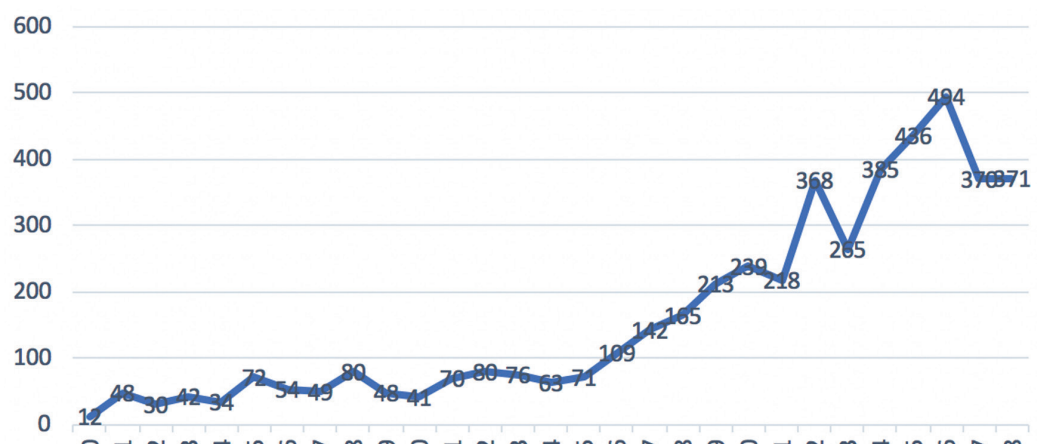

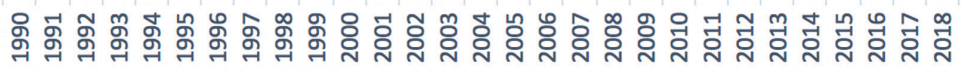

Citas a la revista Munibe AA en distintos medios académicos por año. 